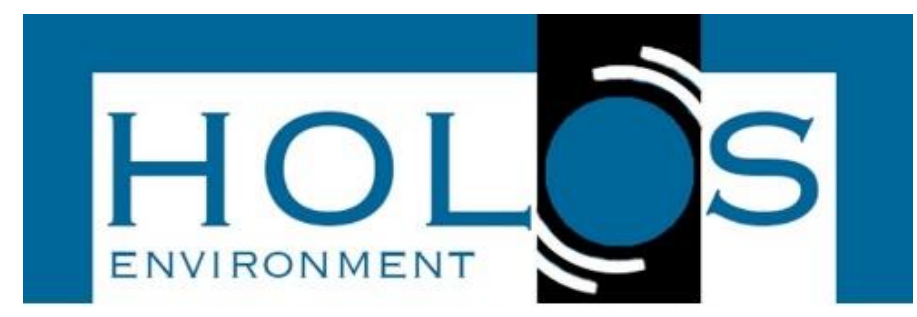

\title{
FLORICULTURA E APROPRIAÇÃO DE RECURSOS HÍDRICOS: UMA ANÁLISE DA UTILIZAÇÃO DAS ÁGUAS SUBTERRÂNEAS PARA A PRODUÇÃO DE FLORES EM HOLAMBRA-SP
}

\author{
FLORICULTURE AND APPROPRIATION OF WATER RESOURCES: AN \\ ANALYSIS OF THE USE OF GROUNDWATER FOR THE PRODUCTION OF \\ FLOWERS IN HOLAMBRA -SP
}

\begin{abstract}
Alan Peterson Lopes ${ }^{1}$
Artigo recebido em: 08/03/2019 e aceito para publicação em: 18/06/2019. DOI: http://dx.doi.org/10.14295/holos.v19i3.12334

Resumo: O presente artigo tem como objetivo analisar a importância da utilização dos recursos hídricos subterrâneos na produção de flores e plantas ornamentais em Holambra-SP. Trata-se de verificar como é realizado o uso da água subterrânea e quais vulnerabilidades territoriais são resultantes. Com apoio de dados do DAEE-SP e de mapeamentos elaborados pelo autor, procura demonstrar a fragilidade do sistema de gestão de recursos hídricos em São Paulo, que aliado à especialização produtiva agrícola provoca situações de estresse hídrico em diversas áreas, tais como o município de Holambra-SP.
\end{abstract}

Palavras-chave: Água. Recursos Hídricos Subterrâneos. Floricultura. Especialização Produtiva. Vulnerabilidade Territorial.

Abstract: This article aims to analyze the importance of the use of groundwater resources in the production of flowers and ornamental plants in Holambra -SP. This is to check how is performed the use of groundwater and which territorial vulnerabilities are arising. With support DAEE -SP data and maps drawn by the author attempts to show the fragility of the water management system in São Paulo, together with the agricultural production specialization causes water stress situations in various areas, such as the municipality of Holambra -SP .

Keywords: Water. Underground Water Resources. Floriculture. Productive Specialization. Territorial Vulnerability.

\section{INTRODUÇÃO}

A agricultura é o setor que mais se utiliza de água no mundo, cerca de $70 \%$ do total consumido. No entanto, em alguns países que tem o setor agrícola como uma das principais atividades econômicas, como é caso do Brasil, este uso pode chegar a 90\% (UNESCO, 2015).

\footnotetext{
${ }^{1}$ Mestre em Geografia pelo Instituto de Geociências e Ciências Exatas da Universidade Estadual Paulista, campus de Rio Claro, SP. E-mail: (alanpetersonlopes@gmail.com)
} 
Dentre as atividades agrícolas que mais consomem água, destaca-se o cultivo de flores e plantas ornamentais. No Brasil esta atividade é relativamente recente, iniciou-se com a chegada dos imigrantes holandeses na década de 1960 e atualmente, ocupa uma área de aproximadamente 14 mil hectares espelhados por todas as unidades da federação.

Sua maior concentração dá-se no estado de São Paulo, com destaque para o município de Holambra, localizado na Região Administrativa de Campinas. Nele existem três cooperativas que controlam grande parte da produção e comércio das flores e plantas ornamentais. Segundo Vieira et. al. (2013), somente a Cooperativa Veiling Holambra $(\mathrm{CVH})$ respondeu por cerca de $45 \%$ de toda a comercialização nacional de plantas ornamentais em 2012, dispondo de mais de seis mil produtos distintos entre espécies e variedades e 400 cooperados.

Uma das principais características da produção de flores e plantas ornamentais é a reduzida área de cultivo, pois apesar do grande número de UPAs produtoras, somente cerca de 360 hectares são destinados à produção no município. Porém, apesar de pequena a área de cultivo, esta atividade necessita de muitos recursos, pois o produto final deve atender aos padrões de qualidade estabelecidos pelo IBRAFLOR (Instituto Brasileiro de Floricultura) com base no mercado externo.

Isto acarreta um uso excessivo de água no município a fim de suprir a produção, visando o atendimento das normas de qualidade estabelecidas. Deste modo, em Holambra há uma grande concentração de pontos de captação de água superficial e subterrânea.

Segundo dados do DAEE (2015), Holambra-SP possui 39 pontos de captação superficial de água e mais 164 pontos de captação subterrânea cadastrados. Deste total, pelo menos 33 pontos de captação superficial de água e 124 de captação subterrânea são exclusivamente destinados ao uso rural no município.

Segundo informações do Escritório de Apoio Técnico - BMT, do Departamento de Águas e Energia Elétrica do Estado de São Paulo (DAEE-SP), estas captações voltadas à irrigação são excessivas e vem ocasionando sérios problemas na disponibilidade hídrica do município. Diversos poços tubulares profundos já vêm demonstrando rebaixamentos drásticos em seus níveis dinâmico e estático. Alguns relatos de usuários também indicaram que muitos poços vêm secando e diminuindo as vazões. 
Diante da necessidade de se gerir adequadamente os recursos hídricos subterrâneos, foi objetivo deste trabalho apresentar um diagnóstico da utilização do Aquífero Tubarão para fins de produção de flores e plantas ornamentais no município de Holambra.

\section{MATERIAL E MÉTODOS}

A preente pesquisa se apoiou nos seguintes instrumentos:

- Levantamento bibliográfico nas bibliotecas da USP, UNESP e UNICAMP.

- Levantamento de dados primários com pesquisas em campo no município de Holambra durante todo o ano de 2014 e início de 2015.

- Entrevistas com produtores da região, com o objetivo de detalhar os processos produtivos e entender a utilização dos equipamentos de irrigação.

- Coleta de dados secundários nas bases do DAEE-SP, IBRAFLOR, CETESB e INPE, além do arquivo municipal de Holambra.

- Coleta de cartas topográficas na base de dados do IBGE e shapefiles na base da CPRM.

- Elaboração de mapas com auxílio do software ARCGIS 10.

\section{RESULTADOS E DISCUSSÕES}

\subsection{Configuração Territorial de Holambra-SP}

O município de Holambra localiza-se nas bacias hidrográficas dos rios Piracicaba, Capivari e Jundiaí (Bacias PCJ) (Mapa 2), na borda centro-leste da Bacia Sedimentar do Rio Paraná. No estado de São Paulo, as Bacias PCJ inserem-se a leste/nordeste, onde fazem divisa com o estado de Minas Gerais e chegam a abranger uma pequena parte de seu território.

Essas bacias hidrográficas são formadas pelo conjunto de três bacias hidrográficas: a bacia do Rio Piracicaba, que possui uma área de drenagem de 12.568 km²; a bacia do Rio Capivari, com área de 1.620 km²; e a bacia do Rio Capivari, com $1.114 \mathrm{~km}^{2}$ de área. 
A geologia desta bacia hidrográfica é bastante complexa, onde predominam o embasamento cristalino na porção leste, constituído por rochas metamórficas e ígneas que apresentam comportamento mais resistente. Na porção central (onde se localiza o município de Holambra) e oeste da Bacia ocorrem rochas sedimentares paleozóicas e mesozóicas em grandes extensões (LOPES, 1994).

O município de Holambra está localizado na província geológica da Depressão Periférica Paulista, entre colinas amplas com topos aplainados, planícies aluviais interiores restritas, drenagem de baixa densidade com padrão subdendrítico em vales abertos (AB'SÁBER, 2008).

Nesta porção das Bacias PCJ ocorre a maior complexidade litológica, onde se pode citar a existência de quatro grupos estratigráficos: o Grupo Tubarão, Grupo Passa Dois, Grupo São Bento e Grupo Bauru.

Holambra está localizada na superfície de afloramento do Grupo Tubarão. O Sistema Aquífero Tubarão localiza-se no centro-sudeste do Estado de São Paulo, estendendo-se desde o Estado de Minas Gerais até o Estado do Paraná com uma área total de $20.700 \mathrm{~km}^{2}$, conforme demonstra o mapa a seguir (Figura 1).

O Grupo Tubarão é composto por rochas sedimentares que datam do período glacial e pós-glacial do Carbonífero Superior e Permiano Médio (LOPES, 1994). Este pacote de rochas pode ser dividido em três formações que estão presentes no Estado de São Paulo: Formação Itararé, Aquidauana e Tatuí.

Na região de Holambra, segundo o perfil litoestatigráfico dos poços tubulares profundos cadastrados no DAEE (Departamento de Águas e Energia Elétrica do Estado de São Paulo), a formação geológica predominante é a Formação Itararé. Em alguns pontos, a Formação Itararé é recoberta por coberturas sedimentares cenozóicas, que podem ser representadas por sedimentos pouco consolidados, incluindo argila, silte e arenitos argilosos e solos residuais (Figura 2). 
Figura 1 - Localização do Sistema Aquífero Tubarão no Estado de São Paulo

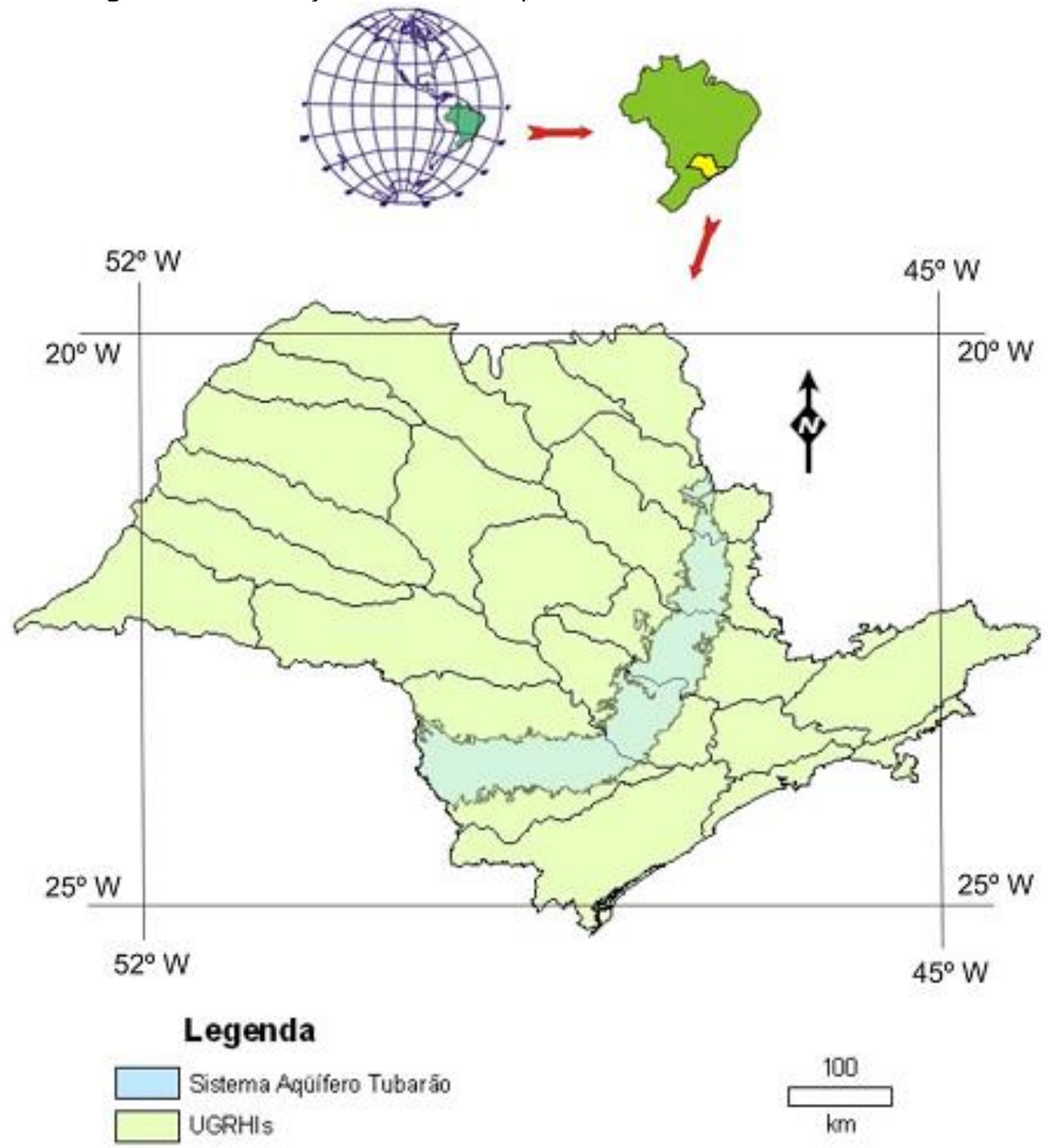

Fonte: ODA et. al. (2013) 
Figura 2 - Mapa Geológico de Holambra

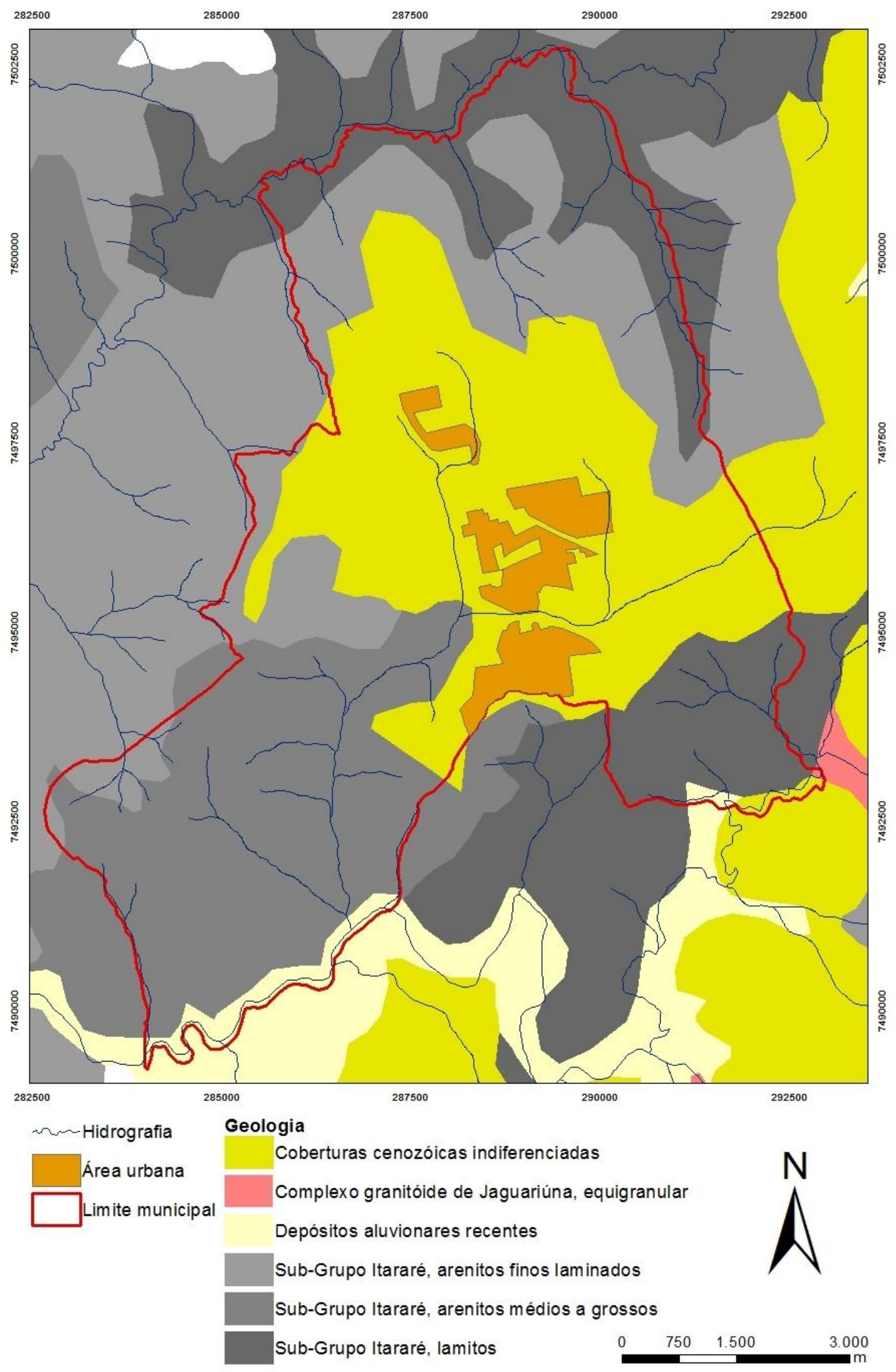

Fonte: Mapa Geológico do Estado de São Paulo - Carta Campinas - 1:250.000 - CPRM 
Segundo Oda et. al. (2005) e Vidal (2002), os sedimentos do Itararé associam-se a diversos subambientes do ambiente glacial, isto é, fluvial, marinho, lacustre, praiano, deltaico, eólicos e outros. Assim sendo, há uma grande diversidade de rochas, tais como diamictitos, tilitos, ritmitos, siltitos, argilitos, folhelhos, conglomerados, arenitos conglomeráticos e sedimentos com presença de carvão. Geralmente, os sedimentos da Formação Itararé possuem coloração que varia de cinza claro a escuro. As litologias predominantes na Formação Itararé são arenitos de granulação heterogênea que são constituídos desde camadas a bancos, com espessuras que podem alcançar várias dezenas de metros.

Toda esta complexidade litológica presente no município de Holambra não favorece a disponibilidade hídrica subterrânea, pois a maioria dessas rochas possui porosidade efetiva muito pequena, o que dificulta muito a explotação de água. Para se calcular a disponibilidade hídrica subterrânea de Holambra levou-se em consideração a capacidade específica do Aquífero Tubarão, a distância de segurança dos poços que deve ser de no mínimo 500 metros neste aquífero, ou seja, quatro poços por $\mathrm{km}^{2}$ e o rebaixamento máximo estipulado em 30 metros, foi elaborada a Equação 1

$Q s=(A .4 . C s .30)$

Onde:

Qs: Disponibilidade Hídrica Subterrânea
A: Área do município
Cs: Capacidade específica subterrânea média

Com relação à capacidade específica ${ }^{2}$ do Sistema Aquífero Tubarão, os parâmetros encontrados (moda, mediana e desvio padrão), segundo pesquisas do DAEE (1981; 1982), Diogo et. al. (1981), IG/SMA (1993; 1995); Oda (1998) e Oda et. al. (2005), foram respectivamente: 0,$1 ; 0,11$; e $0,054 \mathrm{~m}^{3} / \mathrm{h} / \mathrm{m}$, sendo que em Holambra, os valores variam de 0,002 a $0,221 \mathrm{~m} / \mathrm{h} / \mathrm{m}$ (SUPREMA, 2013). A área do município de Holambra é de $65,1 \mathrm{~km}^{2}$.

\footnotetext{
${ }^{2}$ Capacidade específica é a relação entre a vazão extraída de um poço e o respectivo rebaixamento do aqüífero (ABAS, 2014).
} 
Como resultado conclui-se que o município de Holambra oferta $859 \mathrm{~m}^{3} / \mathrm{h}$ de água subterrânea.

\subsection{Sistemas técnicos de captação de água subterrânea na produção florícola holambrense}

Segundo dados do DAEE (2015b), Holambra-SP possui 334 processos de outorga de recursos hídricos, dentre eles, 39 processos referentes à outorga de captação superficial de recursos hídricos e mais 169 processos referentes à outorga de captação subterrânea (Figura 3). Deste total, pelo menos 93 pontos de captação de água são exclusivamente de usuários irrigantes e mais 63 são exclusivos de usuários rurais ${ }^{3}$. Além das captações de água, existem 55 processos referentes à outorga de lançamento de água e 12 processos de outorga de barragens, todas elas relativas à produção agrícola no município (Figura 4).

Figura 3 - Total de processos de outorgas por tipo de uso no munícipio de Holambra no ano de 2015

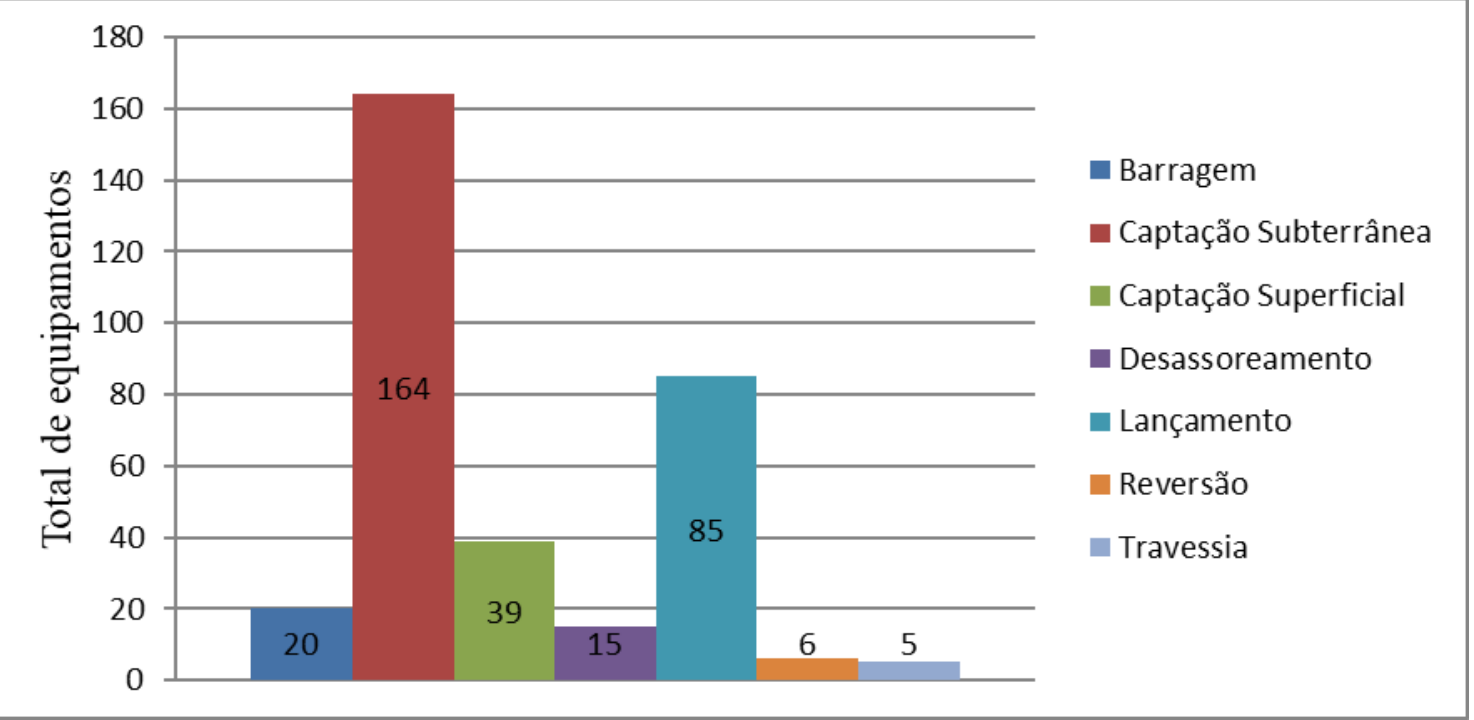

Fonte: DAEE-SP (2015)

${ }^{3}$ A classificação dos usuários de recursos hídricos no DAEE é bastante imprecisa, por isso resolvemos adicionar a informação de usuários rurais, pois dentre eles, com certeza, estão incluídos os irrigantes. 
Figura 4 - Total de outorgas de usuários irrigantes e rurais por tipo de uso, Holambra, 01/2015

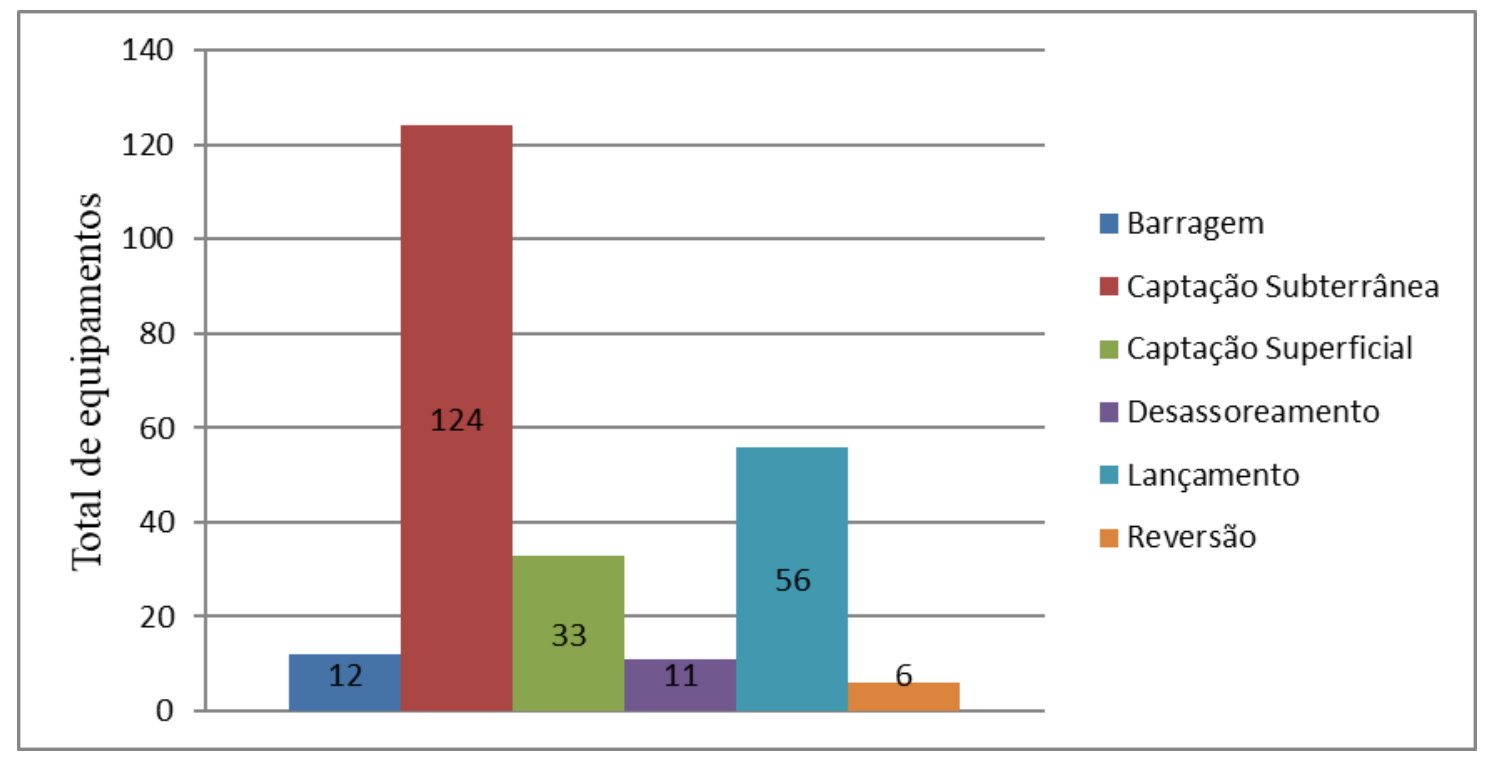

Fonte: DAEE-SP (2015)

É possível notar na Figura 4 que o maior uso de água em Holambra campo é destinado ao uso agrícola, tendo em vista que das 203 outorgas de captação (124 subterrâneas e 39 superficiais), 157 captações (124 subterrâneas e 33 superficiais) são exclusivas para o uso rural. Ainda segundo o DAEE-SP (2015), no município são captados aproximadamente $1.900 \mathrm{~m}^{3} / \mathrm{h}$ de água. Deste total, cerca de 1.265 $\mathrm{m}^{3} / \mathrm{h}$ são exclusivos para irrigação e uso rural. Isto significa que $67 \%$ da água captada, seja de aquíferos ou de rios, são utilizadas para fins agrícolas.

O total de água captada através dos poços cadastrados no DAEE (2015) é de $618,03 \mathrm{~m}^{3} / \mathrm{h}$, sendo a média de produtividade de cada poço de aproximadamente $3,65 \mathrm{~m}^{3} / \mathrm{h}$ e a mediana de $2,0 \mathrm{~m}^{3} / \mathrm{h}$. A grande maioria dos poços (140 poços) possui vazão menor que $6,0 \mathrm{~m}^{3} / \mathrm{h}$ e apenas onze possuem vazão igual ou maior que a vazão potencial de $10 \mathrm{~m}^{3} / \mathrm{h}$ do município de Holambra, estimada por Lopes (1994).

Somente no meio rural, os usos equivalem a um total de 460,36 m³/h de água captada através de poços, ou seja, mais de 2/3 de toda a captação subterrânea do município.

Contudo, vale salientar ainda que nem todos os usos dos recursos hídricos são cadastrados no DAEE. Muitos usuários ainda utilizam a água ilegalmente, principalmente os usuários rurais e irrigantes, devido à dificuldade de fiscalização. 


\subsection{Uso do território e vulnerabilidade hídrica em Holambra}

Conforme demonstrado, o número de poços voltados à irrigação é muito grande e totaliza $2 / 3$ do total do município. Diante disto, torna-se necessário a análise das captações de água subterrâneas no município. A partir disto, elaborou-se o mapa a seguir com o objetivo de demonstrar a localização dos poços em relação às estufas do município (Figura 5).

O emprego da água subterrânea para fins de irrigação da cultura de flroes e plantas ornamentais é perceptível pela proximidade da maior parte dos poços com as estufas (Figura 3). Nota-se que os poços estão distribuídos muito de maneira muito próxima, pois, na maioria das vezes, é necessário mais de um poço para fornecer a quantidade de água necessária às estufas. A elevada densidade de poços observada em Holambra é nociva pois pode alterar significativamente o cenário de disponibilidade hídrica subterrânea no município.

Como Holambra localiza-se na área de afloramento do Sistema Aquífero Tubarão e a litologia deste grupo de rochas não favorece a infiltração e nem o armazenamento de grandes quantidades de água, a perfuração de poços deve respeitar o limite mínimo de 500 metros de distância entre um poço e outro (ODA et. al., 2005). O não respeito a este limite poderá ocasionar interferências na capacidade de explotação de água e provocar drásticos rebaixamentos do nível de água dos poços.

\subsection{Disponibilidade Hídrica X Demanda Hídrica}

Ao compararmos os dados de disponibilidade hídrica e demanda hídrica, a priori, tem-se uma situação favorável, pois a demanda de água, calculada em 618 $\mathrm{m}^{3} / \mathrm{h}$, é menor que a disponibilidade estimada de $859 \mathrm{~m}^{3} / \mathrm{h}$, como mencionado anteriormente. Porém, esta estimativa considerou um cenário onde os poços tubulares respeitam o limite de distância de 500 metros quando localizados no aquífero Tubarão. Isto é, para que a estimativa fosse correta, cada poço deveria estar distante no mínimo 500 metros do outro (ODA et. al., 2005).

Porém, no caso de Holambra, a distância mínima de 500 m não é respeitada. Logo, mesmo a captação de água sendo menor que a estimativa de disponibilidade, a proximidade dos poços altera a situação, pois, como dito, promove interferências na capacidade de explotação de água e provoca um grande rebaixamento nos níveis 
estáticos da água nos aquíferos. A Figura 6 ilustra a distribuição dos poços tubulares profundos cadastrados e seus respectivos raios de interferência.

Figura 5 - Estufas e poços tubulares em Holambra-SP (2015)

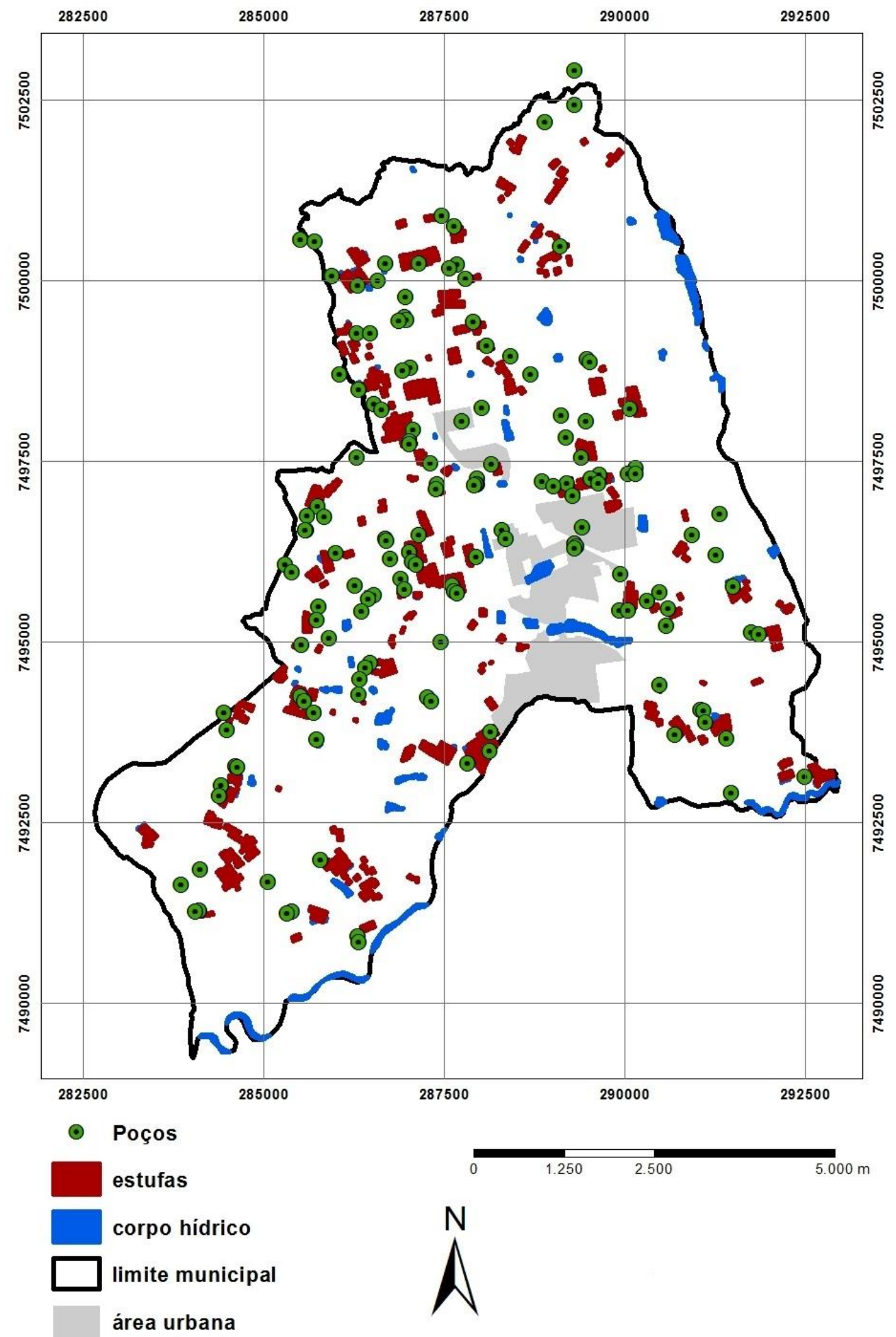

Fonte: DAEE-SP (2015). Elaborado pelo autor. 
Figura 6 - Raios de interferência entre os poços tubulares profundos em Holambra (2015)
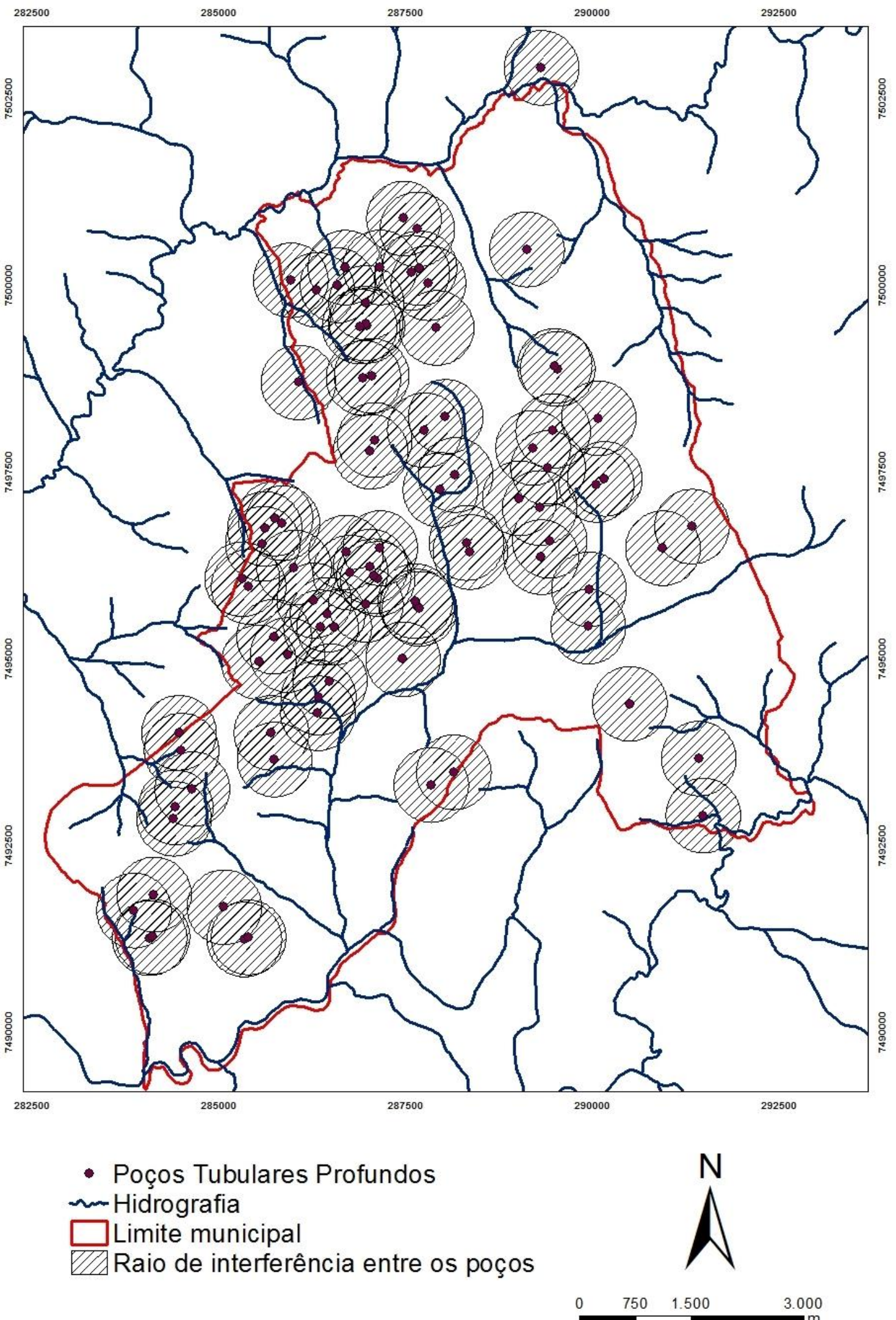

Fonte: DAEE (2015). Elaborado pelo autor 
Este mapa expõe o quão preocupante é a situação de Holambra em relação à disponibilidade hídrica subterrânea. Observa-se que os poços se localizam muito próximo uns aos outros, não respeitando os limites de seus raios de interferência, favorecendo grandes rebaixamentos nos níveis de água ao longo do tempo.

O rebaixamento do nível d'água, além de afetar outros poços, tornando-os improdutivos, pode também impactar na vazão dos rios, principalmente nos meses de estiagem, uma vez que neste período as vazões dos rios são mantidas exclusivamente pelo fluxo de base.

Considera-se então que a dificuldade em se obter boas vazões de água em Holambra pode ser resultado do uso intensivo de água nas estufas para a produção de flores e plantas ornamentais. Isto é, a especialização territorial produtiva florícola é de fato a principal responsável pela situação de escassez hídrica em Holambra.

Vale ressaltar também que os poços representados neste mapa são somente aqueles cadastrados no DAEE, o que faz desta análise uma subestimativa, pois o número de poços clandestinos é significativo. O relatório da SUPREMA, de janeiro de 2013, apontou que existiam ao menos 44 captações subterrâneas irregulares. Entretanto é bastante provável que este número seja ser bem maior, tendo em vista a severa estiagem registradas nos anos de 2013 e 2014 no estado de São Paulo, pressionando os produtores a buscar novas captações de água para não perder sua produção.

A despeito do presente trabalho empregar apenas os poços cadastrados no DAEE, nota-se que estes não respeitam os critérios que deveriam ser utilizados para análise do processo para a obtenção da Portaria de Outorga de Direito de Uso de Recursos Hídricos Subterrâneos, pois a maioria dos poços não respeita o limite de distância de 500 metros.

Portanto, considerando o art. 206 da Constituição do Estado de São Paulo, que prevê que as águas subterrâneas devem ter programas permanentes de conservação e proteção, bem como a Portaria 717, de 12/12/1996, que estabeleceu as normas que disciplinam o uso dos recursos hídricos em São Paulo, a situação de Holambra apresenta graves problemas no gerenciamento dos recursos hídricos subterrâneos.

O próprio DAEE sofre com falta de funcionários e de condições mínimas para análise dos processos de outorga. A demora para a expedição da Portaria de Outor- 
ga ou de um Informe de Indeferimento, muitas vezes, obriga o usuário a realizar a explotação de água ou a perfuração de um poço de maneira ilegal.

Além dos problemas institucionais enfrentados pelo DAEE, a gestão de recursos hídricos no estado de São Paulo enfrenta uma série de outras dificuldades, algumas elencadas a seguir:

- A aprovação recente das normas para uso das águas no Estado de São Paulo (Portaria 717/96) gera alegações que o uso do recurso hídrico é anterior à expedição das normas. Por exemplo, no caso de poços perfurados sem respeitar a distância mínima de 500 metros ou sem ter as adequações necessárias, tais como, revestimento, profundidade, diâmetro, dentre outros, o DAEE-SP não pode obrigar os usuários a tamponá-los, somente a regularizá-los nas condições atuais, ou seja, de qualquer forma, as normas não são respeitadas.

- A falta de estudos mais detalhados sobre disponibilidade hídrica. O DAEE-SP realizou um último estudo na década de 1980 sobre a disponibilidade hídrica de São Paulo que até hoje é utilizado pelos seus técnicos no momento da análise dos processos de outorga;

- A falta de fiscalização;

- Os questionamentos sobre a qualidade e confiabilidade dos dados apresentados nos processos de outorga. A elaboração de tais processos é realizada por empresas de consultoria ambiental, empresas de perfuração de poços ou por profissionais liberais, que apesar de assinarem os processos e expedirem a ART (Anotação de Responsabilidade Técnica) junto ao CREA (Conselho Regional de Engenharia e Arquitetura), podem adulterar alguns documentos, tais como, testes de bombeamento ou análises de água. Estes documentos são apresentados como planilhas de Excel, não havendo possibilidade de algum técnico checar a veracidade destes dados.

Portanto, a situação do uso excessivo de água em Holambra aliado à ingerência do órgão estadual gestor torna o território de Holambra vulnerável em relação aos seus recursos hídricos. O uso excessivo de água para a produção de flores e plantas ornamentais visando atingir os padrões de qualidade pré-estabelecidos exercem uma forte pressão sobre os recursos hídricos no município de Holambra. A escassez de água potável e destinada à irrigação, em função do uso excessivo de 
água subterrânea no município já é perceptível. De acordo com a reportagem do site da Câmara de Holambra de fevereiro de 2014, "a falta de água tem se mostrado extremamente limitante" (CAMARA HOLAMBRA, 2015) para os agricultores familiares em Holambra.

Comprova-se que a especialização territorial produtiva (SILVEIRA, 2011), no caso representada pelo cultivo de flores e plantas ornamentais, e as verticalidades (SANTOS, 2009), representadas pelos padrões de qualidade definidos externamente, impostas trazem vulnerabilidades aos lugares. Os produtores tornam-se reféns de um único produto que é submetido às leis de mercado e ao estabelecimento de padrões de qualidade, provocando graves impactos ambientais. As especializações territoriais produtivas valem-se de um uso predatório e indiscriminado dos recursos do território. No caso de Holambra, a água representa um recurso natural empregado abusivamente para a produção de um único produto visando o atendimento das demandas externas ao lugar.

\section{CONCLUSÕES}

No munícipio de Holambra, ainda que sejam empregados estufas com métodos otimizados de irrigação, a produção de flores e plantas ornamentais está cada vez mais vulnerável devido à exploração desenfreada de recursos hídricos. Esta exploração tem explicação não somente à tendência de especialização produtiva, mas também frente às normas impostas por agentes externos. Estas normas externas, tais como a definição de padrões de qualidade, tornam os produtores reféns do mercado, pois o não atendimento a tais exigências obriga-os a comercializar as flores a preços bem menores nas centrais de abastecimento ou, até mesmo, descartálas totalmente. Diante deste cenário, uma grande quantidade de água é utilizada para criar as condições ideais para o desenvolvimento das plantas e, por fim, para atender aos padrões de qualidade pré-estabelecidos.

Como resultado, foi possível observar que as reservas de água subterrânea estão sendo exploradas de modo abusivo, sem respeitar os limites de distância entre os poços e o tempo de recarga do aquifero.

É necessário, portanto, que se pense em mudanças na matriz produtiva, ou seja, na diversificação da produção como um possível solução à escassez hídrica 
local. Contudo, mudar essa matriz reflete na busca de novos nichos de mercado, que, talvez, não sejam tão lucrativos.

Ainda que se faça necessário pensar a preservação ambiental, a realidade da exploração desenfreada dos recursos naturais em prol do lucro é o principal empeciIho ao estabelecimento de uma relação harmoniosa entre sociedade e meio ambiente.

\section{REFERÊNCIAS}

AB'SÁBER, A. N. Domínios da natureza no Brasil. São Paulo: Annablume, 2008.

DEPARTAMENTO DE ÁGUAS E ENERGIA ELÉTRICA - DAEE. Estudo de águas subterrâneas: região administrativa 5. Campinas, SP: DAEE, 1981.

DEPARTAMENTO DE ÁGUAS E ENERGIA ELÉTRICA - DAEE. Estudo de águas subterrâneas: região administrativa 4. Sorocaba, SP: DAEE, 1981.

DEPARTAMENTO DE ÁGUAS E ENERGIA ELÉTRICA - DAEE. Relatório de Outorgas. Disponível em: www.daee.sp.gov.br. Acesso em: 15 jan. 2015.

CÂMARA HOLAMBRA. Aafhol conta com ONG Suprema e Poder Público para combater escassez de água. Disponível em: http://www.camaraholambra.com.br/?z=noticias\&x=43. Acesso em: 15 mar. 2015.

DIOGO, A.; BERTACHINI, A. C.; CAMPOS, H. C. N. S.; ROSA, R. B. G. S. Estudo preliminar das características hidráulicas e hidroquímicas do Grupo Tubarão no Estado de São Paulo. In: SIMPÓSIO REGIONAL DE GEOLOGIA, 3., 1981. Anais... Curitiba, PR., 1:359-368., 1981.

INSTITUTO GEOLÓGICO / SMA - IG/SMA. Subsídios do meio físico-geológico para o planejamento do município de Campinas, SP. Relatório Técnico. São Paulo: Instituto Geogógico, 1993.

INSTITUTO GEOLÓGICO / SMA - IG/SMA. Diagnóstico do meio físico da Média Bacia do Piracicaba para fins de gestão ambiental. Boletim do Instituto Geológico, n. 13, 1995.

LOPES, M. C. Condições de ocorrência de água subterrânea nas bacias dos rios Piracicaba e Capivari. Dissertação (Mestrado em Recursos Hídricos e Saneamento) - Faculdade de Engenharia Civil. Campinas-SP: UNICAMP, 1994.

LOPES, A. P. Território usado e recursos hídricos: o uso da água na produção de flores e plantas ornamentais em Holambra-SP. Dissertação (Mestrado em Geografia) - Instituto de Geociências e Ciências Exatas. Rio Claro: UNESP, 2015.

ODA, G. H. Contribuição à Hidrogeologia da Região entre Salto e Pirapora de Itu (SP): análise da produtividade, ocorrência e circulação de águas subterrâneas SOS Sistemas Aquíferos Tubarão e Cristalino. Dissertação (Mestrado em Recursos Minerais e Hidrogeologia) - Instituto de Geociências, USP. São Paulo, 1998.

ODA, G. H.; IRITANI, M. A.; FERREIRA, L. M. R.; SILVA, A. H.; ROCHA, G. A. Proposta metodológica para explotação racional do Sistema Aquífero Tubarão no Estado de São Pau- 
lo. In: ENCONTRO NACIONAL DE PERFURADORES DE POÇOS, 14. SIMPÓSIO DE HIDROGEOLOGIA DO SUDESTE, 2., 2005. Anais... Ribeirão Preto, 2005. CD-ROM, 13 p.

SANTOS, M. A Natureza do espaço: técnica e tempo, razão e emoção. 4. ed. São Paulo: Editora da Universidade de São Paulo, 2009.

SILVEIRA, M., L.. Território usado: dinâmicas de especialização, dinâmicas de diversidade. Ciência Geográfica, Bauru, v. 15, n. 1, jan. dez., 2011.

SUPREMA (ASSOCIAÇÃO DE PRESERVAÇÃO DO MEIO AMBIENTE). Estudo técnico visando diagnosticar a situação dos recursos hídricos destinados à exploração de água no município de Holambra-SP, compatibilizando alternativas entre disponibilidade e demandas hídricas. Holambra-SP: SHS, 2013.

UNITED NATIONS EDUCATIONAL, SCIENTIFIC AND CULTURAL ORGANIZATION UNESCO. World Water Balance and Water Resources of the Earth. Paris: UNESCO Press, 1978.

VIDAL, A. C. Estudo Hidrogeológico do Aqüífero Tubarão na área de afloramento da porção central do Estado de São Paulo. Tese (Doutorado) - Instituto de Geociências e Ciências Exatas, UNESP, Rio Claro, 2002.

VIEIRA, G. C., SOUZA, A. S., BORGES, A. C. G. Análise da floricultura no Estado de São Paulo sob a ótica do modelo estrutura-conduta-desempenho. In: Simpósio de Engenharia de Produção, 20., 2013. Anais... Bauru-SP, 2013. 